\title{
Patterns of adolescent gun carrying and gun-related crime arrests in Indianapolis, Indiana over an 11-year time period
}

Lauren A. Magee, $\mathrm{PhD}^{1}$, Allyson L. $\mathrm{Dir}^{2,3}, \mathrm{PhD}$, Richelle L. Clifton ${ }^{4}$, BS, Sarah E. Wiehe ${ }^{1}$, MD, MPH, Matthew C. Aalsma, $\mathrm{PhD}^{3}$

${ }^{1}$ Children's Health Services Research, Department of Pediatrics, Indiana University School of Medicine, Indianapolis, Indiana

${ }^{2}$ Department of Psychiatry, Indiana University School of Medicine, Indianapolis, Indiana

${ }^{3}$ Adolescent Behavioral Health Research Program, Department of Pediatrics, Indiana University School of Medicine, Indianapolis, Indiana

${ }^{4}$ Department of Psychology, Indiana University Purdue University, Indianapolis, Indiana

\section{Corresponding author info:}

Direct correspondence to Lauren A. Magee, Department of Pediatrics, Indiana University School of Medicine, $410 \mathrm{~W} .10^{\text {th }}$ Street, Indianapolis, Indiana 46202 (e-mail: lamagee@ iu.edu)

Word Count: 1850 words/1 Table

Abstract:

Adolescent males are disproportionately affected by homicide as both victims and offenders. Indianapolis has seen increases in youth homicides over the past few years; gun carrying increases an individual's risk for involvement in firearm violence. It is unclear how often youth are arrested for gun carrying and gun-related crimes. Examining these patterns may identify an opportunity for intervention. This study is a descriptive epidemiology analysis that examines patterns of gun carrying and gun-related crime arrests among justice involved youth in Marion County (Indianapolis), Indiana. We accessed juvenile court records from January 1, 2006 to December 31, 2016 on all individuals arrested for a gun carrying offense (i.e., illegal possession of a firearm or gun; $\mathrm{n}=711$ ) and all individuals arrested for a gun-related crime (i.e., homicide, robbery, aggravated assault; $\mathrm{n}=150$ ). Data were analyzed in fall 2019. Proportions of juvenile arrests for both gun carrying (47.0 per 1,000 arrests) and gun-related crime (25.4 per 1,000 arrests) have substantially increased compared to ten-years ago ( 4.5 per 1,000 arrests and 2.0 per 1,000 arrests, respectively). Of those arrested, 27.7 per 100,000 population were arrested for a repeated gun-related offense; of which 21.5 per 100,000 were first arrested for gun carrying and 6.2 per 100,000 were arrested for a gun-related crime. The majority of gun-related repeat offenders were first arrested for gun carrying; therefore, these gun-carrying arrests may be an opportunity to intervene on an individual level by providing treatment, other needed resources, and discussing safe firearm storage with families and communities.

This is the author's manuscript of the article published in final edited form as:

Magee, L. A., Dir, A. L., Clifton, R. L., Wiehe, S. E., \& Aalsma, M. C. (2020). Patterns of adolescent gun carrying and gun-related crime arrests in Indianapolis, Indiana over an 11-year time period. Preventive Medicine, 106199. https://doi.org/10.1016/j.ypmed.2020.106199 
Acknowledgements. We would like to thank the Marion County Superior Court Juvenile Division for allowing our team access to arrest data. Moreover, we would like to thank Juvenile Probation Director, Chris Ball, and Deputy Director, Kevin Riley, for their support of Marion County youth and their insight on juvenile arrest data quality.

Funding. The study was supported by grants through the U.S. DHHS, Health Resources and Services Administration, Maternal and Child Health Research Program (R40MC08721, PI: Matthew C. Aalsma) as well as the Agency for Healthcare Research and Quality (R01HS022681, PI: Matthew C. Aalsma; R01HS023318, PI: Sarah E. Wiehe).

There are no conflicts of interest to disclose 


\section{Abstract:}

Adolescent males are disproportionately affected by homicide as both victims and offenders. Indianapolis has seen increases in youth homicides over the past few years; gun carrying increases an individual's risk for involvement in firearm violence. It is unclear how often youth are arrested for gun carrying and gun-related crimes. Examining these patterns may identify an opportunity for intervention. This study is a descriptive epidemiology analysis that examines patterns of gun carrying and gun-related crime arrests among justice involved youth in Marion County (Indianapolis), Indiana. We accessed juvenile court records from January 1, 2006 to December 31, 2016 on all individuals arrested for a gun carrying offense (i.e., illegal possession of a firearm or gun; $n=711$ ) and all individuals arrested for a gun-related crime (i.e., homicide, robbery, aggravated assault; $n=150$ ). Data were analyzed in fall 2019. Proportions of juvenile arrests for both gun carrying (47.0 per 1,000 arrests) and gun-related crime (25.4 per 1,000 arrests) have substantially increased compared to ten-years ago (4.5 per 1,000 arrests and 2.0 per 1,000 arrests, respectively). Of those arrested, 27.7 per 100,000 population were arrested for a repeated gun-related offense; of which 21.5 per 100,000 were first arrested for gun carrying and 6.2 per 100,000 were arrested for a gun-related crime. The majority of gun-related repeat offenders were first arrested for gun carrying; therefore, these gun-carrying arrests may be an opportunity to intervene on an individual level by providing treatment, other needed resources, and discussing safe firearm storage with families and communities.

Word Count: 1850

Introduction

Gun violence is a leading public health problem in the United States. Homicide is a leading cause of death among individuals 10-19 years of age; furthermore, firearms accounted for the cause of death in $87 \%$ of homicides among this group in 2016 (Curtin, Heron, Minino, \& Warner, 2018). African American males are disproportionately affected by gun violence compared to other racial groups (Kalesan, French, Fagan, Fowler, \& Galea, 2014), which contributes to significant health inequalities. Youth who are exposed to violence are at high risk of gun carrying (Beardslee et al., 2018) and victimization (Papachristos, Braga, \& Hureau, 2012; Papachristos, Wildeman, \& Roberto, 2015). Further, gun carrying increases the risk of 
involvement with the criminal justice system (Braga \& Cook, 2016); juvenile arrests and subsequent incarcerations have considerable effect on juvenile health. In fact, adolescent offenders face a higher likelihood of mortality at each level of the justice system; from arrest, to juvenile detention, to incarceration, and youths waived to adult court face the highest risk of morality (Aalsma et al., 2016).

Researchers have studied factors influencing youth gun carrying using self-report surveys (Beardslee et al., 2018; Dong \& Wiebe, 2018; Oliphant et al., 2019); however, little is understood about patterns of arrests for gun carrying and gun-related crimes among youth. The total number of adolescent arrests in the United States decreased by $59 \%$ between 2008 and 2017, and adolescent arrests for weapon law violations are at their lowest since 1980 (Puzzanchera, 2019). Despite the overall decline across the United States, there has been a 23\% increase in youth arrested for homicide between 2012 and 2017, which are largely committed with a gun. In Indianapolis, Indiana, in 2014 and 2015 the rate of homicide victims between the age of 10 - 19 years of age was 10.9 per 100,000 population, compared to 2018 and 2019 when the rate increased to 20.2 per 100,000 population (FBI). Further, the city has experienced increases in gun related homicides; the rate of gun homicides in 2018 and 2019 was 18.9 per 100,000 population compared to 10.6 per 100,000 in 2014 and 2015 (IndyStar, 2018).

The purpose of this descriptive analys is is to examine patterns and differences between gun carrying and gun-related crime arrests among justice-involved youth in Indianapolis. Given the high prevalence of gun violence among youth and the harmful impact that involvement with the criminal justice system has on health; understanding the patterns and differences of gun carrying and gun-related crimes may have important policy implications. Intervening with youth arrested for gun carrying may prevent future violent perpetration or death resulting from a gun. 
Methods

The Marion County Superior Court Juvenile Division (MCJD), in Marion County (Indianapolis), Indiana, collects person-level data for each criminal charge when a youth under the age of 18 is arrested. For this analysis, we accessed electronic records from January 1, 2006 to December 31, 2016 on all individuals arrested for a gun carrying offense (i.e., illegal possession of a firearm or gun; $n=711$ ) and all individuals arrested for a gun-related crime (i.e., homicide, robbery, aggravated assault; $n=150$ ). There were 63 individuals who were arrested more than once during the study time period; 33 of those individuals were arrested for both a gun carrying and a gun-related crime but during two different arrest events. No single juvenile arrest had both a gun carrying offense and gun-related crime. Gun-related crimes were defined by Federal Bureau of Investigation Uniform Crime Reporting standards and included carjacking, murder, armed robbery, battery by deadly weapon, and using a dangerous weapon (Investigation, 2004). Arrests for murder were included as all juvenile homicides in Indianapolis were committed with a gun during this time period. Other variables included demographics of each arrested individual (i.e., sex, race/ethnicity, age) and dichotomous variables denoting placement in juvenile detention, probation, probation required program assignment (e.g., mental health, drug programs), probation conditions (e.g., electronic monitoring), and probation outcome. We assessed changed by year using date of arrest.

We used calculated population-based arrest rates per 100,000 youth for each gun arrest category. We calculated yearly population-based denominators using data from the American Community Survey (ACS). Given the ACS does not have race-and-sex specific population estimates, we used data from the 2010 Census, multiplied by the 11 -year study period. Over the study period there was an average of 227,483 adolescents living within Marion County. From 
2006 to 2016 there was a population increase of 5,584 adolescents within Marion County and the boundaries of Marion County have not changed. We also calculated the proportion of yearly arrest rates per 1,000 juvenile arrests for both gun carrying and gun-related crime arrests to assess differences over time. We then assessed rates per 100,000 population and differences by demographics and placement across gun carrying and gun-related crime arrests using chi-square and independent t-tests using Stata (StataCorp, 2015). Data were analyzed in the fall of 2019 and received IRB approval from Indiana University.

Results

Over the 11-year time period, 312.6 per 100,000 population $(n=711)$ youth were arrested for a gun carrying offense ( $n=759$ arrests) and 65.9 per 100,000 population $(n=150)$ youth were arrested for a gun-related crime ( $\mathrm{n}=161$ arrests); 27.7 per 100,000 population $(n=63)$ individuals had repeat arrests for gun carrying and/or gun-related crimes. Of those individuals with a repeat offense, 21.5 per 100,000 population $(n=49)$ were first arrested for gun carrying and 6.2 per 100,000 population $(n=14)$ were first arrested for a gun-related crime. Repeat arrest rates were 24.6 per 100,000 population $(n=56)$ for a gun carrying arrest and 7.8 per 100,000 population $(\mathrm{n}=17)$ for a gun-related crime arrest.

The yearly arrest rate per 100,000 population for gun carrying arrests in 2010 was 36.4 per 100,000 population, the rate decreased in 2012 through 2015 , then increased to a rate of 37.6 per 100,000 population in 2016 . Gun-related crime arrests per 100,000 population was 4.4 per 100,000 in 2011 , decreased to 2.6 and 2.2 per 100,000 population in 2012 and 2013 , then substantially increased in 2014 - 2016 to a rate of 20.3 per 100,000 population in 2016 (Figure 1). 
The proportion of both gun carrying and gun-related crime arrests compared to total arrests has substantially increased over the 11-year time period (Table 1). For instance, guncarrying arrests among youth increased from 17.7 per 1,000 adolescent arrests in 2013 to 46.9 per 1,000 in 2016 and gun-related crime arrests increased from 8.32 per 1,000 adolescent arrests in 2013 to 25.4 in 2016. (p <0.05).

Youth arrested for gun-related crimes $(\mathrm{M}=13.6$ years, $\mathrm{SD}=2.02)$ were slightly younger at first arrest than youth arrested for gun carrying $(M=14.3$ years, $S D=2.03 ; p<0.05)$. The arrest rate for gun-carrying was higher for minorities at 57.4 per 100,000 population compared to 6.9 for white youth, and 57.2 for males compared to 2.6 for females per 100,000 population. The rate per 100,000 population for gun-related crimes was 12.6 for minorities, compared to 1.1 for whites. Males also had a higher rate at 11.6 per 100,000 population compared to females at 1.1 for gun-related crime arrests. Specifically, youth arrested for gun-carrying were $76.7 \%$ African American, $16.5 \%$ white, $1.5 \%$ Hispanic, and 5.3\% multi-racial. Of those arrested for a gunrelated crime, $82.0 \%$ were African American, $11.8 \%$ white, and 6.2\% multi-racial.

Youth were more likely to be placed in juvenile detention for gun-related crimes, compared to gun carrying arrests $(\mathrm{p}<0.05)$. Youth arrested for gun-related crimes were more likely to be assigned to mental health and drug-related programs, compared to youth arrested for gun carrying ( $\mathrm{p}<0.05$ and $\mathrm{p}<0.05$, respectively). When stratified by race; African American youth were more likely to be assigned to mental health programs, compared to White youth $(\mathrm{p}<0.05)$; whereas, White youth were more likely to be assigned to drug-related programs, compared to African American youth ( $\mathrm{p}<0.05$, respectively). There were no statistically significant differences observed for youth assigned to electronic monitoring or probation across the two groups or by race. 


\section{Discussion}

The current study found the proportion of gun related arrested compared to total adolescent arrests has substantially increased from 2013 to 2016. The majority of youth arrested for a gun related offense were minority males highlighting the known disparities that exist in those effected by gun violence (Kalesan et al., 2014). Additionally, the majority of youth who are repeat offenders were arrested first for gun carrying. These arrests may be an opportunity to divert at-risk youth to appropriate treatment or other needed resources instead of processing them through the criminal justice system, as processing youth through the system may actually increase future delinquency (Petrosino, Turpin- Petrosino, \& Guckenburg, 2010).

The point of arrest is also an opportunity to implement prevention efforts such as firearm safety and firearm storage with both youth and families. For example, safe storage practices have shown some promise in decreasing adolescent firearm injuries (Violano et al., 2018). Further, community-based firearm safety events among individuals who own guns may be opportunities to educate gun owners about safe storage practices (King et al., 2020).

The point of arrest is also a critical period to discuss gun acquisition with youth. Currently, when an adolescent is arrested with a gun, the gun is confiscated and is not returned to the adolescent upon release; however, little is done at the time of arrest to understand how youth obtain their weapons (Webster, Meyers, \& Buggs, 2014). According to the Survey of Inmates in State Correctional Facilities, nearly $40 \%$ of youth obtain their weapons from family or friends (Wintemute, Braga, \& Kennedy, 2010); however, additional efforts are needed to better understand other means of obtaining guns. 
This study should be interpreted with its limitations in mind. First, the descriptive nature of the analysis limits our understanding of causal mechanisms contributing to youth involvement with guns. Our arrests rates may be an undercount given we used a population denominator of under 18 and children under the age of eight are not typically arrested. Moreover, this study only examined youth arrested for gun carrying and gun-related crimes, and does not include youth who carry firearms and are not arrested. Given the longitudinal nature of these data arrest policy and statute changes may influence the patterns we have observed. There was a statue change in July 2008, which ensured juveniles would only be waived to adult court for felony offenses (I.C. 31-30-1-2), however, these changes should not affect arrest patterns. Despite the limitations, these analyses, make an important contribution towards understanding the patterns in adolescent involvement in gun carrying and gun-related crimes within an urban environment that has seen recent increases in adolescent homicides.

Conclusions

In Indianapolis, young minority males are most at risk for being involved in gun carrying and gun-related crimes, which is likely contributing to the increase in adolescent homicide victims. Although public health and focused deterrence efforts such as Indianapolis Violence Reduction Partnership (Chermak \& McGarrell, 2004) work, programs should focus more on prevention efforts. This study identified gun-carrying arrests as a possible opportunity divert youth to appropriate treatment and resources but also to engage youth, families, and communities in conversations about safe gun storage. Lastly, public health interventions and policies should focus on further understanding the environmental and other risk factors that may increase access to guns. 
References

Aalsma, M. C., Lau, K. S., Perkins, A. J., Schwartz, K., Tu, W., Wiehe, S. E., . . Rosenman, M. B. (2016). Mortality of youth offenders along a continuum of justice system involvement. American journal of preventive medicine, 50(3), 303-310.

Beardslee, J., Mulvey, E., Schubert, C., Allison, P., Infante, A., \& Pardini, D. (2018). Gun- and Non-Gun-Related Violence Exposure and Risk for Subsequent Gun Carrying Among Male Juvenile Offenders. J Am Acad Child Adolesc Psychiatry, 57(4), 274-279. doi:10.1016/j.jaac.2018.01.012

Braga, A. A., \& Cook, P. J. (2016). The criminal records of gun offenders. Geo. JL \& Pub. Pol'y, 14, 1.

Chermak, S., \& McGarrell, E. (2004). Problem-solving approaches to homicide: An evaluation of the Indianapolis Violence Reduction Partnership. Criminal Justice Policy Review, 15(2), 161-192.

Curtin, S. C., Heron, M., Minino, A., \& Warner, M. (2018). Recent Increases in Injury Mortality Among Children and Adolescents Aged 10-19 Years in the United States: 1999-2016. National vital statistics reports : from the Centers for Disease Control and Prevention, National Center for Health Statistics, National Vital Statistics System, 67(4).

Dong, B., \& Wiebe, D. J. (2018). Violence and beyond: Life-course features of handgun carrying in the urban United States and the associated long-term life consequences. Journal of Criminal Justice, 54, 1-11. doi:10.1016/j.jcrimjus.2017.11.002

FBI. Supplementary Homicide Reports.

IndyStar. (2018). Indianapolis Crime: List of all criminal homicides.

Investigation, F. B. (2004). Uniform crime reporting handbook. Retrieved from https://www2.fbi.gov/ucr/handbook/ucrhandbook04.pdf: Federal Bureau Investigation

Kalesan, B., French, C., Fagan, J. A., Fowler, D. L., \& Galea, S. (2014). Firearm-related hospitalizations and in-hospital mortality in the United States, 2000-2010. Am J Epidemiol, 179(3), 303-312. doi:10.1093/aje/kwt255

King, A., Simonetti, J., Bennett, E., Simeona, C., Stanek, L., Roxby, A. C., \& Rowhani-Rahbar, A. (2020). Firearm storage practices in households with children: a survey of communitybased firearm safety event participants. Preventive Medicine, 131, 105952.

Oliphant, S. N., Mouch, C. A., Rowhani-Rahbar, A., Hargarten, S., Jay, J., Hemenway, D., . . . Consortium, F. (2019). A scoping review of patterns, motives, and risk and protective factors for adolescent firearm carriage. Journal of behavioral medicine, 42(4), 763-810.

Papachristos, A. V., Braga, A. A., \& Hureau, D. M. (2012). Social networks and the risk of gunshot injury. J Urban Health, 89(6), 992-1003. doi:10.1007/s11524-012-9703-9

Papachristos, A. V., Wildeman, C., \& Roberto, E. (2015). Tragic, but not random: the social contagion of nonfatal gunshot injuries. Soc Sci Med, 125, 139-150. doi:10.1016/j.socscimed.2014.01.056

Petrosino, A., Turpin-Petrosino, C., \& Guckenburg, S. (2010). Formal system processing of juveniles: Effects on delinquency. Campbell Systematic Reviews, 6(1), 1-88.

Puzzanchera, C. (2019). Juvenile Arrests, 2017. Retrieved from Office of Justice Programs: StataCorp. (2015). Stata Statistical Software: Release 14. In. College Station, TX: StataCorp LP. 
Violano, P., Bonne, S., Duncan, T., Pappas, P., Christmas, A. B., Dennis, A., .. . Shillinglaw, W. (2018). Prevention of firearm injuries with gun safety devices and safe storage: an Eastern Association for the Surgery of Trauma Systematic Review. Journal of Trauma and Acute Care Surgery, 84(6), 1003-1011.

Webster, D. W., Meyers, J. S., \& Buggs, M. (2014). Youth acquisition and carrying of firearms in the United States: Patterns, consequences, and strategies for prevention. Paper presented at the Proceedings of Means of violence workshop, forum of global violence prevention. Washington, DC: Institutes of Medicine of the National Academies.

Wintemute, G. J., Braga, A. A., \& Kennedy, D. M. (2010). Private-party gun sales, regulation, and public safety. New England journal of medicine, 363(6), 508-511. 
Table 1: Descriptive statistics of individuals arrested for gun-carrying and gun-related crimes and overall rates of gun arrests compared to total arrests in Indianapolis, Indiana

*Calculated based on number of gun arrests/total adolescent arrests

\begin{tabular}{|c|c|c|c|}
\hline Demographics & $\begin{array}{c}\text { Gun-carrying } \\
\text { arrests } \\
n=759\end{array}$ & $\begin{array}{c}\text { Gun-related crime } \\
\text { arrests } \\
\mathrm{n}=161\end{array}$ & $\begin{array}{l}\text { p-value (gun-carrying } \\
\text { v gun-related) }\end{array}$ \\
\hline Race & $\%$ & $\%$ & $\mathrm{P}=$ ='s 0.287 \\
\hline Minority & 88.4 & 91.3 & \\
\hline White & 11.6 & 8.70 & \\
\hline Sex & & & $\mathrm{P}=$ 's 0.018 \\
\hline Male & 95.8 & 91.3 & \\
\hline Female & 4.22 & 8.70 & \\
\hline $\begin{array}{l}\text { Average Age at First } \\
\text { Arrest (mean, IQR) }\end{array}$ & $14.3(9,14,18)$ & $13.6(8,14,18)$ & $\mathrm{P}=$ 's 0.000 \\
\hline \multicolumn{4}{|l|}{ Placement } \\
\hline Juvenile Detention & 25.8 & 53.4 & $\mathrm{P}=$ 's 0.000 \\
\hline Electronic Monitoring & 67.2 & 61.5 & $\mathrm{P}=$ 's 0.165 \\
\hline Probation $(n=574, n=109)$ & 75.6 & 67.7 & $\mathrm{P}=$ ='s 0.334 \\
\hline Successfully Completed & 53.7 & 48.6 & \\
\hline $\begin{array}{l}\text { Unsuccessfully } \\
\text { Completed }\end{array}$ & 46.3 & 51.4 & \\
\hline Mental Health Program & 28.6 & 39.8 & $\mathrm{P}=$ 's 0.005 \\
\hline Drug Program & 11.7 & 18.0 & $P=' s 0.030$ \\
\hline & \multicolumn{3}{|c|}{ Proportions of Gun arrests per 1,000 total adolescent arrests* } \\
\hline Year & $\begin{array}{l}\text { Gun-carrying } \\
\text { arrests }\end{array}$ & $\begin{array}{l}\text { Gun-related crime } \\
\text { arrests }\end{array}$ & Total Gun arrests \\
\hline 2006 & 4.45 & 2.04 & 6.50 \\
\hline 2007 & 5.65 & 1.65 & 7.30 \\
\hline 2008 & 17.49 & 1.53 & 19.0 \\
\hline 2009 & 23.13 & 1.37 & 24.51 \\
\hline 2010 & 26.52 & 1.03 & 27.55 \\
\hline 2011 & 22.23 & 2.71 & 24.95 \\
\hline 2012 & 16.64 & 1.81 & 18.45 \\
\hline 2013 & 17.73 & 1.50 & 19.24 \\
\hline 2014 & 28.53 & 8.32 & 36.85 \\
\hline 2015 & 34.82 & 17.89 & 52.71 \\
\hline
\end{tabular}


Figure 1: Adolescent gun arrest rates per 100,000 population in Indianapolis, Indiana, 2006-2016

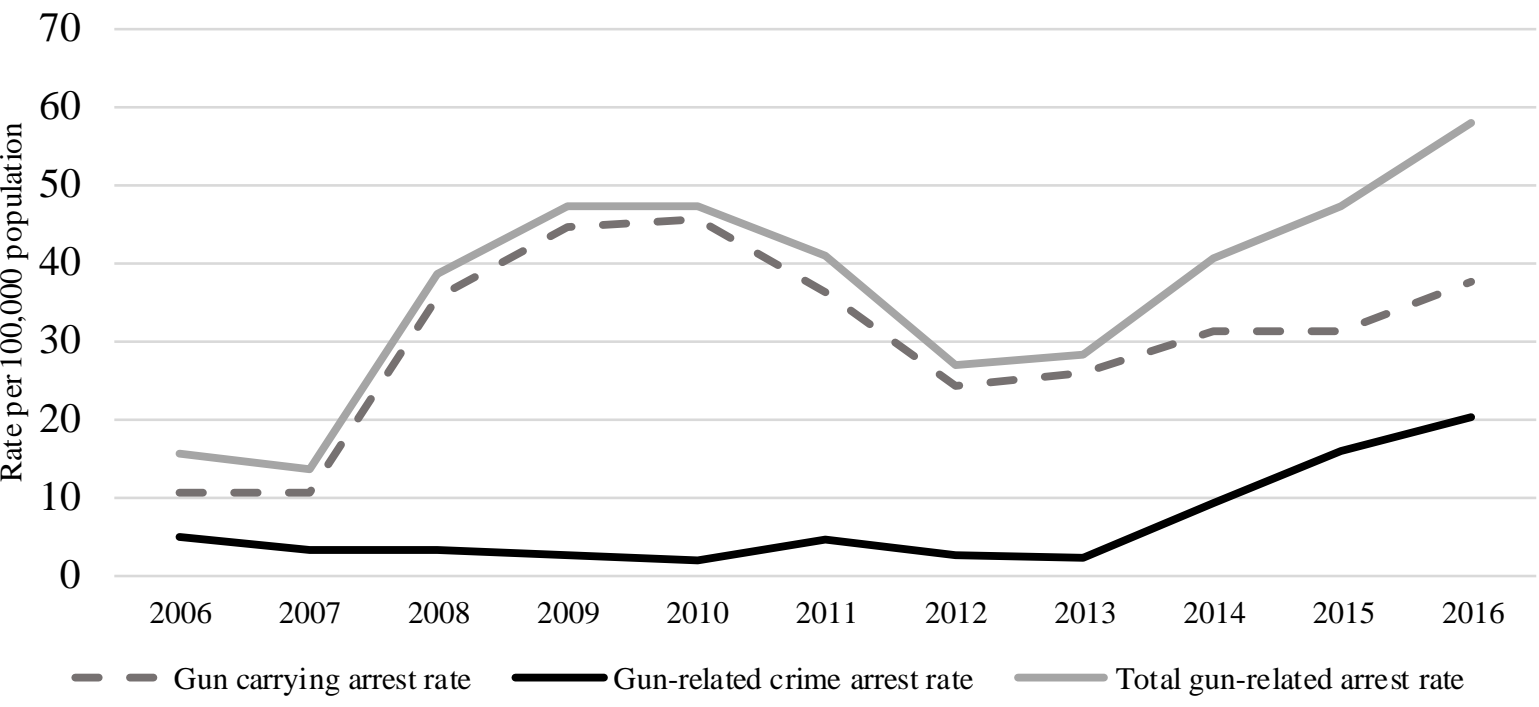




\section{Author statement}

LM, AD and MA conceptualized the study. LM analyzed data, drafted original manuscript. LM, $\mathrm{AD}, \mathrm{RC}, \mathrm{SW}, \mathrm{MA}$ interpreted results, assisted in editing and writing manuscript. All authors read and approved final manuscript. 